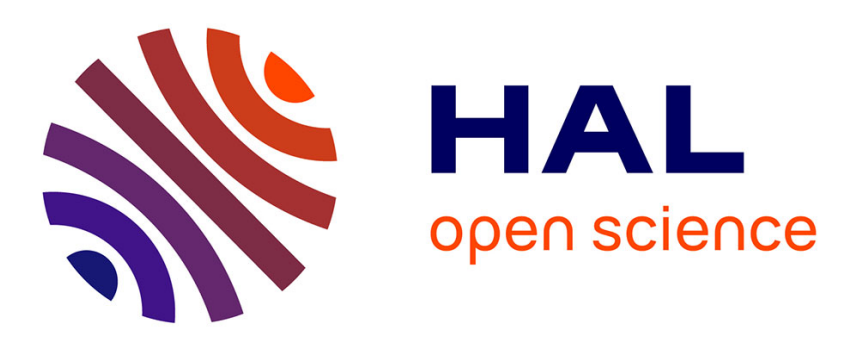

\title{
Preparation of TiO, thin films by pulsed laser deposition for waveguiding applications
}

\author{
C. Garapon, C. Champeaux, J. Mugnier, G. Panczer, P. Marchet, A.
} Catherinot, B. Jacquier

\section{- To cite this version:}

C. Garapon, C. Champeaux, J. Mugnier, G. Panczer, P. Marchet, et al.. Preparation of TiO, thin films by pulsed laser deposition for waveguiding applications. Applied Surface Science, 1996, 96-98, pp.836 - 841. 10.1016/0169-4332(95)00593-5 . hal-02296069

\section{HAL Id: hal-02296069 \\ https://hal-unilim.archives-ouvertes.fr/hal-02296069}

Submitted on 5 Jun 2020

HAL is a multi-disciplinary open access archive for the deposit and dissemination of scientific research documents, whether they are published or not. The documents may come from teaching and research institutions in France or abroad, or from public or private research centers.
L'archive ouverte pluridisciplinaire HAL, est destinée au dépôt et à la diffusion de documents scientifiques de niveau recherche, publiés ou non, émanant des établissements d'enseignement et de recherche français ou étrangers, des laboratoires publics ou privés. 


\title{
Preparation of $\mathrm{TiO}_{2}$ thin films by pulsed laser deposition for waveguiding applications
}

\author{
C. Garapon ${ }^{\mathrm{a},{ }^{*}, \text { C. Champeaux }}{ }^{\mathrm{b}}$, J. Mugnier $^{\mathrm{a}}$, G. Panczer $^{\mathrm{a}}$, P. Marchet $^{\mathrm{b}}$, A. Catherinot $^{\mathrm{b}}$, B. Jacquier ${ }^{\mathrm{a}}$ \\ a Laboratoire de Physico-Chimie des Mat\&au Luminescents- UMR 5620 CNRS, Université Lyon I. 43, Bd du I1 \\ Novembre 1918, 69622 Villeurbanne Cedex, France \\ b Laboratoire de Matériaux Céramiques et Traitements de Surface - URA 320 CNRS, Université de Limoges, \\ 123, au. Albert Thomas, 87060 Limoges Cedex, France
}

\begin{abstract}
$\mathrm{TiO}_{2}$ thin films have been deposited on $\mathrm{SiO}_{2} / \mathrm{Si}, \mathrm{MgO}$ and $\mathrm{Al}_{2} \mathrm{O}_{3}$ substrates by Pulsed Laser Deposition with a $\mathrm{KrF}$ excimer laser from a rutile ceramic target. From X-ray diffraction and Raman spectroscopy, their crystalline structure appear to be mainly anatase. The potentialities of waveguiding properties have been evaluated by measuring refractive index and thickness with m-line spectroscopy.

\section{Introduction}

$\mathrm{TiO}_{2}$ is an important material for optical applications (as antireflective coating for example) and $\mathrm{TiO}_{2}$ thin films have been grown by a number of techniques, each one of them emphasizing different advantages [1]. Surprisingly there are only few reports on Pulsed Laser Deposition (PLD) of $\mathrm{TiO}_{2}$ [2-4], though the interest of this technique has been well recognized. If optical waveguide fabrication and characterization are extensively studied for integrated optics applications, PLD technique has only very recently been used, and only for nonlinear optical materials such as $\mathrm{LiNbO}_{3}[5,6]$. The aim of this study is to show the feasibility of growing by $\mathrm{PLD} \mathrm{TiO}_{2}$ thin films suitable for optical waveguiding applications.
\end{abstract}

\section{Thin films deposition}

The experimental set-up has already been described [7]. We give only the main parameters of the deposition procedure. The beam of a $\operatorname{KrF}$ excimer laser $(\mathrm{A}=248 \mathrm{~nm})$ was focussed on the rotating target with a fluence of $3 \mathrm{~J} / \mathrm{cm}^{2}$. The temperature of the substrate, heated by an halogen lamp, was $790^{\circ} \mathrm{C}$. The base pressure in the deposition chamber was $4 \times 10^{-8}$ mbar but the film deposition took place in an oxygen pressure of $10^{-1} \mathrm{mbar}$. The cooling of the films was achieved in a 200 mbar pressure of oxygen. The targets have been prepared from $\mathrm{TiO}_{2}$ rutile powder with very fine grains (around $10 \mathrm{~nm}$ ), compressed and sintered at $1050^{\circ} \mathrm{C}$ in air up to $56 \%$ of the bulk density, keeping the rutile structure as checked by X-ray diffraction (XRD) and Raman spectroscopy (see Section 3.2). Films have been grown on carefully cleaned monocrystalline substrates: MgO (100), Si covered with a $\mathrm{SiO}_{2}$ amorphous layer, about $1 \mu \mathrm{m}$ thick, and $\mathrm{Al}_{2} \mathrm{O}_{3}$. The discussion will concentrate more specifically on these samples.

The thickness of the films was determined with a Sloan Dektak IIA profilometer. Films of less than $1 \mu \mathrm{m}$ thickness have been obtained after a $40 \mathrm{mn}$ deposition. Optical microscopy observations show that the samples have good transparency and are homogeneous, crack-free, with no droplets. Some films have been grown under other conditions (Table I) and the influence of the deposition parameters will be discussed briefly in the next section.

\section{Structural characterization}

$\mathrm{TiO}_{2}$ exists in three different crystalline phases: anatase, rutile (both tetragonal) and brookite (orthorhombic). Amorphous $\mathrm{TiO}_{2}$ crystallises upon heating into anatase, which transforms into rutile above about $700^{\circ} \mathrm{C}$. Depending on the deposition techniques and parameters, it is possible to obtain amorphous $\mathrm{TiO}_{2}$ (for low substrate temperature generally) or the anatase and rutile phases or both, with various proportions, orientations and crystal sizes $[1,8]$. For the structural characterization we used X-ray diffraction and Raman spectroscopy.

\subsection{X-ray diffraction}

Fig. 1 shows the XRD diagrams of $\mathrm{TiO}_{2}$ thin films deposited on $\mathrm{SiO}_{2} / \mathrm{Si}$, and $\mathrm{MgO}$ substrates, registered with a Siemens D500 diffractometer $(\lambda \mathrm{Cu} \mathrm{K} \alpha=1.540 \mathrm{~A}$, graphite back-monochromator $)$. In the case of $\mathrm{SiO}_{2} / \mathrm{Si}$ substrate the spectrum contains essentially the (004) line of anatase with very weak (101) and (200) lines. The film is thus constituted of partially oriented anatase crystals, the preferential orientation of the $c$-axis being perpendicular to the film surface. A small amount of rutile is also detected, as some weak rutile lines, (101), (111) and (211) are observed.

For the film deposited on the oriented $\mathrm{MgO}$ substrate, besides the very intense line due to the (200) plane of $\mathrm{MgO}$, the same (004) anatase line is predominant in the spectrum. The same preferential orientation of the $c$ - 
axis of the anatase crystals, perpendicular to the film surface, is obtained. In addition weak (112) and (200) lines are observed for anatase. The contribution of rutile, detected by the (200) and (111) lines, is weak.

\subsection{Raman spectroscopy}

The films were investigated using a Dilor X-Y modular multichannel laser Raman spectrometer equipped with a confocal microscope (backscattering configuration). The exciting wavelength is $514.5 \mathrm{~nm}$. With the used objective ( X 50), the analysed area has a diameter of about $10 \mu \mathrm{m}$.

Fig. 2 compares the Raman spectra of the rutile target and the film deposited on $\mathrm{SiO}_{2} / \mathrm{Si}$. The target exhibits the characteristic rutile spectrum in this range [9], with bands at $612 \mathrm{~cm}^{-1}\left(\mathrm{~A}_{1 \mathrm{~g}}\right), 447 \mathrm{~cm}^{-1}\left(\mathrm{E}_{\mathrm{g}}\right)$, and 143 $\mathrm{cm}^{-1}\left(\mathrm{~B}_{1 \mathrm{~g}}\right)$. The 235 and $360 \mathrm{~cm}^{-1}$ lines are attributed to multiphonon scattering. The spectrum of the film, besides the $521.5 \mathrm{~cm}^{-1}$ line due to the Si substrate, is mainly constituted by the anatase spectrum [10]: $639 \mathrm{~cm}^{-1},\left(\mathrm{E}_{\mathrm{g}}\right), 516$ $\mathrm{cm}^{-1}\left(\mathrm{~A}_{1 \mathrm{~g}}-\mathrm{B}_{1 \mathrm{~g}}\right), 399 \mathrm{~cm}^{-1}\left(\mathrm{~B}_{1 \mathrm{~g}}\right), 197 \mathrm{~cm}^{-1}\left(\mathrm{E}_{\mathrm{g}}\right), 144 \mathrm{~cm}^{-1}\left(\mathrm{E}_{\mathrm{g}}\right)$. Two weak bands at 618 and $442 \mathrm{~cm}^{-1}$ show that some amount of rutile phase is also present. Changing the polarization of the exciting laser beam does not modify significantly the relative line intensities. This is in agreement with a preferential orientation of the $c$-axis perpendicular to the film surface, taking into account the polarization selection rules for the Raman spectrum of anatase [10].

Fig. 3 gives the Raman spectra of the film grown on a $\mathrm{MgO}$ substrate for two polarizations. The anatase spectra are recognized, with a weak rutile contribution. The change in the relative intensities of the lines with polarization indicates that the $c$-axis preferential orientation perpendicular to the film surface is less well defined than for the $\mathrm{SiO}_{2} / \mathrm{Si}$ substrate. All these results are in agreement with those of X-ray diffraction. However further information may be obtained, as will be discussed below.

\section{Discussion}

It is interesting to notice first that, under these deposition conditions $\left(0.1\right.$ mbar of $\mathrm{O}_{2}, 790^{\circ} \mathrm{C}$ as substrate temperature), the predominant phase is anatase, though its growth takes place at a temperature above that at which it is supposed to begin to transform into rutile $\left(700^{\circ} \mathrm{C}\right)$. However, if rutile is the thermodynamically stable phase, anatase may be kinetically stable until about $1000^{\circ} \mathrm{C}$, depending on the grain size for example. Such a situation is similar to that of sol-gel thin films where anatase alone has been observed even after annealing at $900^{\circ} \mathrm{C}$ [11].

Another point of interest is that anatase has a preferential orientation of the $c$-axis perpendicular to the film surface, for both a monocrystalline substrate, $\mathrm{MgO}$, and an amorphous one, $\mathrm{SiO}_{2}$, deposited on $\mathrm{Si}$. The film deposited on $\mathrm{Al}_{2} \mathrm{O}_{3}$ is amorphous according to XRD, but shows some of the rutile and anatase lines in the Raman spectrum. As the coherent domain sizes for the two processes should be different, it may be inferred that very small and/or imperfect crystallites are present.

For films \#l and \#2 the width of the anatase main line at $144 \mathrm{~cm}^{-1}$ is broaden relative to that of the bulk crystal $\left(14 \mathrm{~cm}^{-1}\right.$ instead of $\left.7 \mathrm{~cm}^{-1}\right)$ [12]. The line width can be related to the mean size of the crystals, which could be of the order of $10 \mathrm{~nm}$ as it has been observed for anatase powders [13] and in anatase thin films deposited by the sol-gel method [11].

Our results differ from previous reports on $\mathrm{TiO}_{2}$ deposition on $\mathrm{Si}$ wafers, as could be expected for different deposition parameters. Depositions with a YAG laser at $532 \mathrm{~nm}$ under vacuum lead to polycrystalline rutile films for a substrate temperature of $850^{\circ} \mathrm{C}$, with a few anatase phase at $500^{\circ} \mathrm{C}$. Films grown at lower substrate temperatures are amorphous [2], as those deposited with an $\mathrm{ArF}$ laser at substrate temperature less than $200^{\circ} \mathrm{C}$, under various $\mathrm{O}_{2}$ pressures [3]. At last, for a deposition with an $\mathrm{ArF}$ laser at $450^{\circ} \mathrm{C}$ without introduction of $\mathrm{O}_{2}$, rutile is obtained with a (200) orientation and when increasing the $\mathrm{O}_{2}$, pressure from $0.1 \mathrm{~T}$ to $0.3 \mathrm{~T}$, one goes from rutile (with (110) and (200) lines) to anatase (with (101) and (004) main lines) [4].

Preliminary results on the influence of deposition parameters for a $\mathrm{MgO}$ substrate (Table 1) show that rutile is preponderant at higher laser fluence, higher oxygen pressure and if a rutile ceramic target prepared with coarser grains is used. Better understanding of the deposition process could result from the study of the nature and energy of the species present in the plume [14].

\subsection{Optical characterization}

The optical waveguiding potentiality has been tested by the dark m-line spectroscopy, the principle of which is briefly recalled. The beam of an He-Ne laser $(\lambda=632.8 \mathrm{~nm})$ is coupled into the film with the aid of a rutile prism (angle: 45.38 degrees): for discrete values of the incidence angle, the evanescent wave, existing in the air gap between the prism and the film, may excite the guided modes in the film. The coupling is detected by the apparition of dark lines in the reflected beam and the effective index may be calculated for each mode [15].

For sample \#1 $\left(\mathrm{TiO}_{2}\right.$ on $\mathrm{SiO}_{2} / \mathrm{Si}$ ) five $\mathrm{TE}$ (transverse electric) modes and only three $\mathrm{TM}$ (transverse magnetic) modes are observed due to a low coupling efficiency. Assuming a step index profile, the thickness $(930 \mathrm{~nm})$ and the refractive index $(\mathrm{n}=2.219)$ have been deduced from the TE modes. For sample \#2 $\left(\mathrm{TiO}_{2}\right.$ on $\mathrm{MgO}$ ) four TE and four TM modes are pointed, but, as for sample \#1, the dark lines are large (up to 0.5 degree), inducing a low precision of the measurements. Both TE and TM observations provide a thickness of $870 \pm 3 \mathrm{~nm}$. 
The refractive index are ranging from 2.23 (TE) to 2.25 (TM) which is in agreement with an anisotropy of the layer observed by XRD and Raman spectroscopy. Though light coupling into the film could be achieved with a prism, it was not possible to detect any propagation on a significant distance. This can be due to several reasons: surface roughness, porosity at the scale of the wavelength, as the refractive index is smaller than for the bulk crystals $\left(\mathrm{n}_{0}=2.605, \mathrm{n}_{\mathrm{e}}=2.899\right.$ for rutile, $\mathrm{n}_{0}=2.488, \mathrm{n}_{\mathrm{e}}=2.561$ for anatase, at $\left.589.3 \mathrm{~nm}\right)$.

For the film \#4 $\left(\mathrm{TiO}_{2}\right.$ on $\mathrm{MgO}$ deposited at lower temperature) two dark lines, very sharp (less than 0.05 degree), are observed for the TE, and TM, modes. As this film is thin (less than $200 \mathrm{~nm}$ ) due to a shorter deposition time, only the first two modes exist, which does not allow the calculation of the thickness and refractive index. The good quality of this film is attested by the sharpness of the lines. In this case a good hope exists of observing guided wave propagation. Unfortunately, due to the small size of the sample $\left(5 \mathrm{X} 5 \mathrm{~mm}^{2}\right)$, this could not be checked. At last, waveguiding over a distance of about $1 \mathrm{~cm}$ was observed in $\mathrm{TiO}_{2}$ film \#3 on $\mathrm{Al}_{2} \mathrm{O}_{3}$.

\section{Conclusion}

We have grown $\mathrm{TiO}$, thin films on $\mathrm{MgO}, \mathrm{SiO}_{2} / \mathrm{Si}$ and $\mathrm{Al}_{2} \mathrm{O}_{3}$ substrates by PLD from rutile ceramic targets. The films are mainly constituted by small crystals of anatase, r-utile or both, depending on the deposition parameters. These crystals are partially oriented, as characterized by X-ray diffraction and micro-Raman spectroscopy. We measured their thickness and refractive index by $\mathrm{m}$-line spectroscopy. Favorable waveguiding properties may be expected, depending on substrate and film structure.

\section{Acknowledgements}

We are indebted to R.S.A. LeRubis for graciously providing us with the sapphire substrate. We would like to thank very much Pr. M. Boudeulle for helpful discussions, C. Urlacher for m-line data treatment and R. Vera for carrying out X-ray diffractometry.

\section{References}

[1] J.M. Bennett et al., Appl. Opt. 28 (1989) 3303.

[2] M.Y. Chen and P.T. Murray, Mater. Res. Sot. Symp. Proc. 191 (1990) 43.

[3] H.A. Durand, J.H. Brimaud, O. Hellman, H. Shibata, Y. Makita, D. Gesbert and P. Meyrueis, Appl. Surf. Sci. 86 (1995) 122.

[4] H. Funakoshi, K. Fumato, M. Okuyama and Y. Hamakawa, Jpn. J. Appl. Phys. 33 (19941 5262.

[S] P. Aubert, G. Garry, R. Bisaro and F.J. Garcia, Appl. Surf. Sci. 86 (1995) 144.

[6] J.M. Liu. Z.G. Liu, S.N. Zhu and Z.C. Wu, Mater. Lett. 20 (1994) 35.

[7] C. Champeaux, P. March\&, J. Aubreton, J.P. Mercurio and A. Catherinot, Appl. Surf. Sci. 69 (1993) 335.

[8] P. Lobl, M. Huppertz and D. Mergel, Thin Solid Films 251 (1994) 72.

[9] S.P.S. Porto, P.A. Fleury and T.C. Damen, Phys. Rev. 154 (1967) 522.

[10] T. Ohsaka, F. Irumi and Y. Fujiki, J. Raman Spectrosc. 7 (1978) 321.

[11] M. Bahtat, J. Mugnier, L. Lou and J. Serughetti, SPIE Sol-Gel Optics II 1758 (1992) 173.

[12] T. Ohsaka, J. Phys. Sot. Jpn. 48 (1980) 1661.

[13] E. Vasseur, These d'universite, Lille (1994).

[14] C. Champeaux, D. Damiani, C. Girault, P. Marchet, J. Aubreton, J.P. Mercurio and A. Catherinot, in: Laser Ablation of Electronic Materials: Basic Mechanisms and Applications, Eds. E. Fogarassy and S. Lazare (NorthHolland, Amsterdam, 1992).

[15] D. Uhich and R. Torge, Appl. Opt. 12 (1973) 2901. 


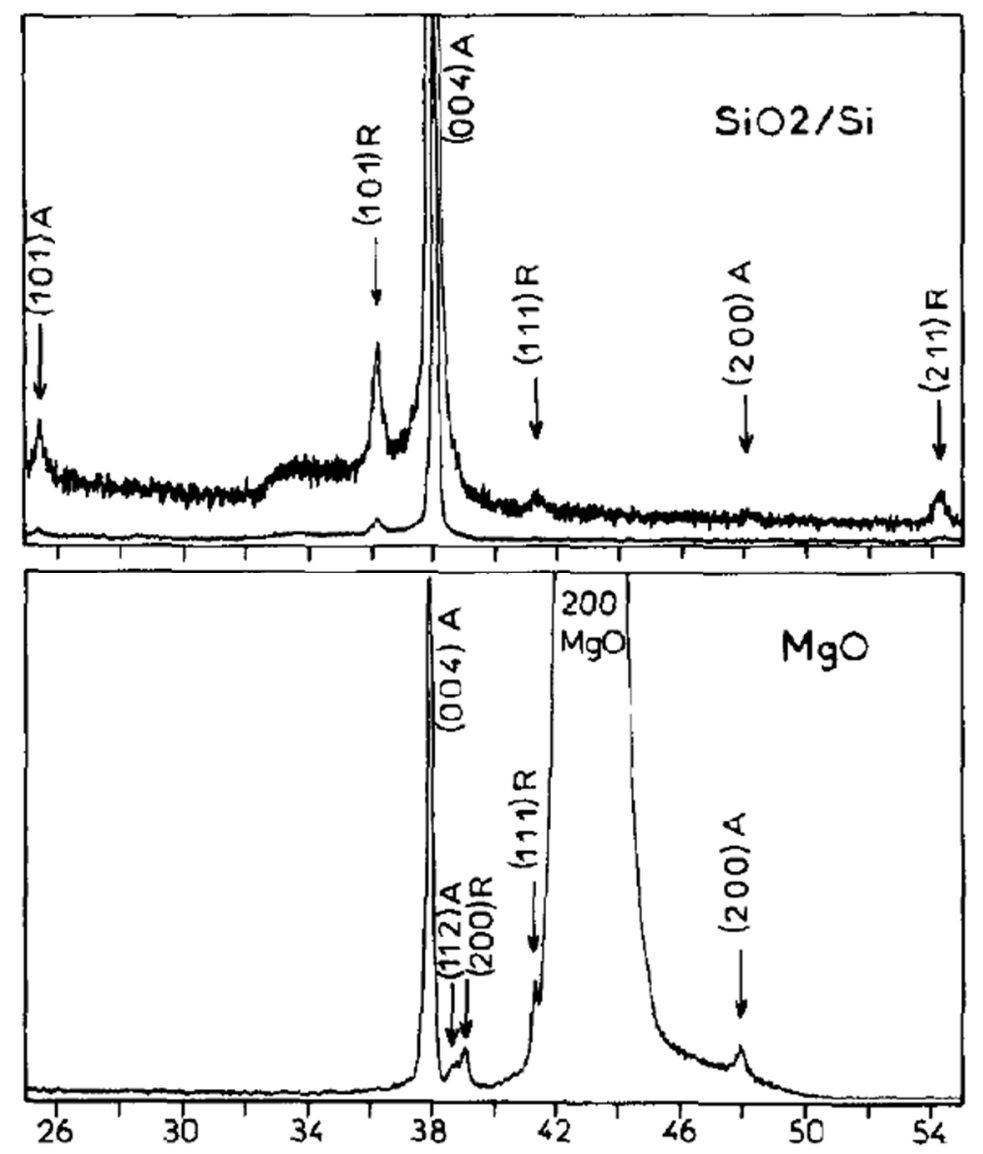

Fig. 1. X-ray diffraction diagrams of $\mathrm{TiO}_{2}$ films deposited on $\mathrm{SiO}_{2} / \mathrm{Si}$ and $\mathrm{MgO}$

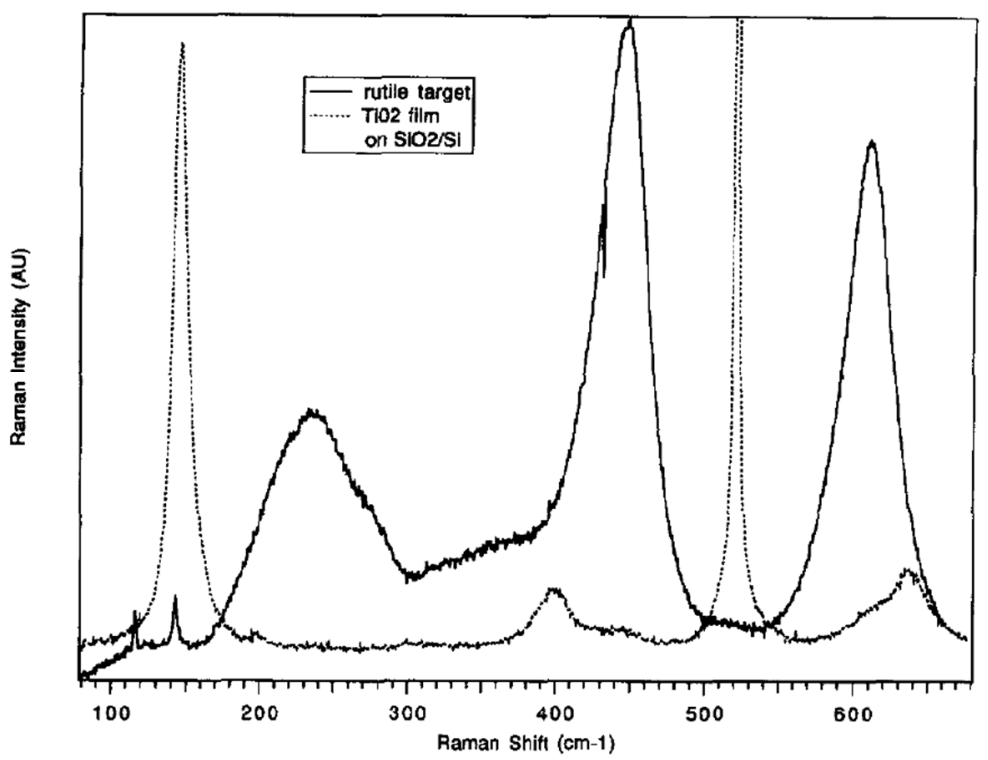

Fig. 2. Raman spectra of the rutile target and $\mathrm{TiO}_{2}$ films on $\mathrm{SiO}_{2} / \mathrm{Si}$ 


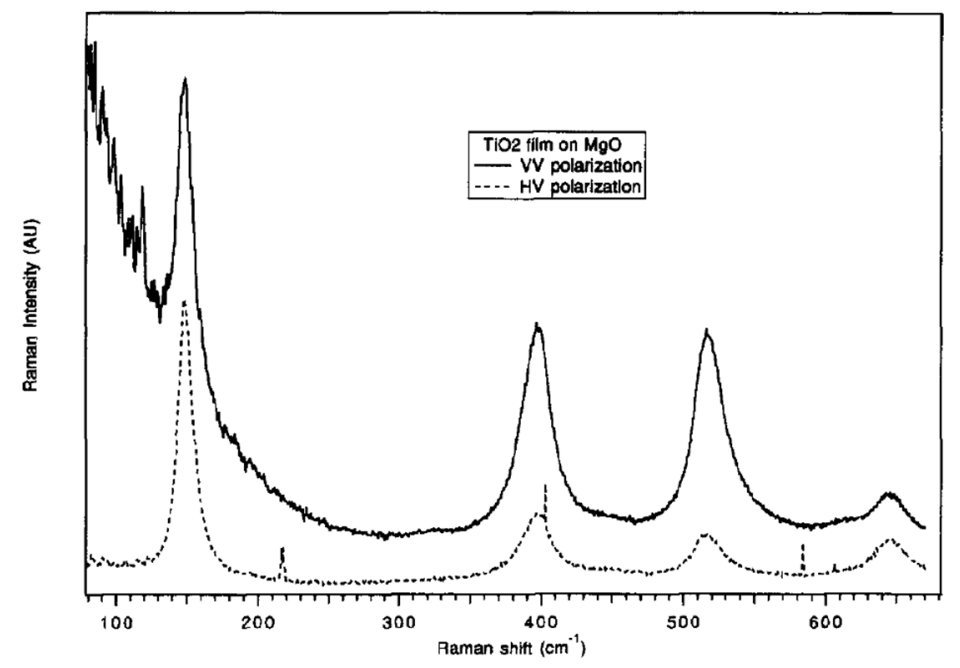

Fig. 3. Raman spectra of $\mathrm{TiO}_{2}$ film \#1 deposited on $\mathrm{MgO}$.

Table 1 : Deposition parameters of the samples and predominant crystalline phase observed by X-ray diffraction and Raman spectroscopy

\begin{tabular}{llllllll}
\hline Sample & Substrate & $\begin{array}{l}\text { Substrate } \\
\text { temperature } \\
\left({ }^{\circ} \mathrm{C}\right)\end{array}$ & $\begin{array}{l}\text { Oxygen } \\
\text { pressure } \\
\text { (mbar) }\end{array}$ & $\begin{array}{l}\text { Ceramic } \\
\text { target }\end{array}$ & $\begin{array}{l}\text { Laser } \\
\text { fluence } \\
\left(\mathrm{J} / \mathrm{cm}^{2}\right)\end{array}$ & $\begin{array}{l}\text { Predominant } \\
\text { crystalline } \\
\text { phase }{ }^{\mathrm{a}}\end{array}$ \\
\hline 3 & $\mathrm{MgO}(100)$ & 790 & $10^{-1}$ & rutile & 3 & $\mathrm{Rx}$ & Raman \\
\hline 2 & $\mathrm{SiO}_{2} / \mathrm{Si}$ & 790 & $10^{-1}$ & rutile & 3 & $\mathrm{~A}$ & $\mathrm{~A}$ \\
3 & $\mathrm{Al}_{2} \mathrm{O}_{3}$ & 790 & $10^{-1}$ & rutile & 3 & $\mathrm{~A}$ & $\mathrm{~A}+\mathrm{R}$ \\
4 & $\mathrm{MgO}$ & 600 & $3 \times 10^{-1}$ & rutile & 3 & $\mathrm{R}$ & - \\
5 & $\mathrm{MgO}$ & 790 & $3 \times 10^{-1}$ & rutile & 3 & $\mathrm{R}$ & - \\
6 & $\mathrm{MgO}$ & 790 & $10^{-1}$ & rutile & 3 & $\mathrm{R}$ & $\mathrm{R}$ \\
7 & $\mathrm{MgO}$ & 790 & $10^{-1}$ & rutile & 6 & $\mathrm{R}$ & $\mathrm{R}$ \\
\hline
\end{tabular}

a: rutile, A: anatase, am: amorphous.

${ }^{b}$ Cuarse grains. 